\title{
An Unusual Giant Pleomorphic Adenoma of Submandibular Salivary Gland: A Rare Case Report
}

\author{
Bela J Prajapati ${ }^{1}$, Shalu Gupta ${ }^{2}$, Devang P Gupta ${ }^{3}$, Viral J Prajapati ${ }^{4}$, Chaitry K Shah ${ }^{5}$
}

\begin{abstract}
Pleomorphic adenoma is the most common benign tumor of salivary glands. Eighty percent of pleomorphic adenomas occur in the parotid gland, $10 \%$ in the submandibular gland, and $10 \%$ in minor salivary glands and sublingual glands. In this case report, we aim to present the unusually giant presentation of submandibular gland pleomorphic adenoma and its management of a 52-year-old female patient who presented to us with a swelling in the right submandibular region for the last 5 years. Fine needle aspiration cytology (FNAC) suggested salivary gland origin. Ultrasonography of the neck revealed a well-defined large lobulated heterogeneous echotexture lesion with few cystic areas within and showing internal vascularity in the right submandibular region. Computed tomography (CT) scan revealed a large lobulated heterogeneously enhancing mass of $15 \mathrm{~cm} \times 13 \mathrm{~cm}$ in the right submandibular region. The patient underwent right submandibular gland mass excision under general anesthesia. The patient presented good aesthetic and functional results with no clinical and radiographic evidence of recurrence. Being painless and slowly growing, some patients neglect it to such large sizes especially if surgery was a psychological setback for them which can then lead to facial disfigurement and severe pressure symptoms which may be fatal. Giant pleomorphic adenoma of the submandibular gland is a rare finding and should be diagnosed cautiously. Proper treatment is complete surgical excision with removal of the fibrous capsule so as to prevent recurrence.
\end{abstract}

Keywords: Fine needle aspiration cytology, Mixed tumor, Pleomorphic adenoma.

Otorhinolaryngology Clinics: An International Journal (2020): 10.5005/jp-journals-10003-1346

\section{BACKGROUND}

Pleomorphic adenoma is the most common benign tumor of salivary glands. ${ }^{1}$ It can also be classified as a mixed tumor since it has both epithelial and mesenchymal components as seen on histology. Majority of pleomorphic adenomas occur in the largest salivary gland, i.e., the parotid (80\%), $10 \%$ in the submandibular gland, and $10 \%$ in sublingual glands and minor salivary glands. ${ }^{2}$ Pleomorphic adenoma of the submandibular gland is more common in women between 40 years and 60 years of age usually presenting as a painless hard mass. ${ }^{3}$ Histologically, it is an encapsulated tumor that is covered by a thin capsule that forms around the salivary gland parenchyma due to fibrosis secondary to mass effect, known as a pseudocapsule. ${ }^{4}$ The standard line of treatment for these tumors is surgical excision. ${ }^{5}$ In this case report, we aim to present the unusually giant presentation of submandibular gland pleomorphic adenoma and its management.

\section{Case Description}

A 52-year-old female patient presented with a swelling in the right submandibular region for the last 5 years. The swelling was initially small in size and slow-growing but started growing rapidly in the last 6 months. The swelling was painless. The patient did not have any difficulty in swallowing, breathing, or change of voice. On clinical examination, there was a firm, nontender, multilobulated bosselated swelling crossing the midline measuring approximately $15 \mathrm{~cm} \times 13 \mathrm{~cm}$ in the right submandibular area. The swelling was mobile and the skin over the swelling showed dilated blood vessels (Fig. 1). No lymph nodes were palpable. Oral cavity and oropharynx examination were within normal limits. Indirect laryngoscopy examination was normal. The origin of the mass could not be determined clinically
${ }^{1,3-5}$ Department of ENT, BJ Medical College and Civil Hospital, Ahmedabad, Gujarat, India

${ }^{2}$ Department of ENT, BJ Medical College, Ahmedabad, Gujarat, India

Corresponding Author: Shalu Gupta, Department of ENT, BJ Medical College, Ahmedabad, Gujarat, India, Phone: +91 9099097966, e-mail: shalz.581989@gmail.com

How to cite this article: Prajapati BJ, Gupta S, Gupta DP, et al. An Unusual Giant Pleomorphic Adenoma of Submandibular Salivary Gland: A Rare Case Report. Int J Otorhinolaryngol Clin 2020;12(1):14-16.

Source of support: Nil

Conflict of interest: None

whether it arose from the parotid, submandibular, or even thyroid gland. Fine needle aspiration cytology (FNAC) suggested a salivary gland origin (Fig. 1).

Ultrasonography of the neck revealed a well-defined large lobulated heterogeneous echotextured lesion with few cystic areas within and showing internal vascularity in the right submandibular region. Fine needle aspiration cytology of mass revealed epithelial cells arranged in poorly cohesive clusters, sheets, and branching fronds in a fibrillary chondromyxoid background with the cells being plasmacytoid, uniform with regular ovoid nuclei, bland nuclear chromatin, and well-defined cytoplasm suggestive of pleomorphic adenoma. Computed tomography (CT) scan revealed a large lobulated heterogeneously enhancing mass of $15 \mathrm{~cm} \times 13 \mathrm{~cm}$ in the right submandibular region causing mass effect over the internal jugular vein and right common carotid artery with multiple feeding vessels inside the mass appearing to be arising from the right external carotid artery. Few calcified granulomas were in the bilateral lung field, and the rest $\mathrm{CT}$ thorax was within normal limits (Figs 2 and 3). 


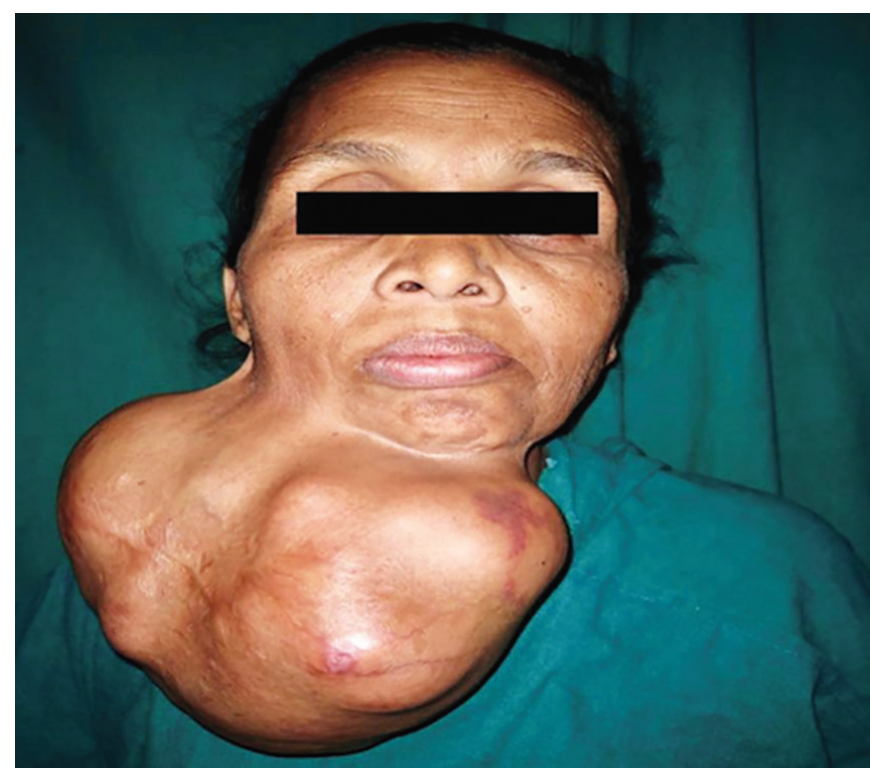

Fig. 1: Clinical picture of the patient with a right submandibular mass

The patient underwent right submandibular gland mass excision under general anesthesia. The right inferolateral elliptical incision was kept to separate the tumor from neck great vessels. After securing them, dissection was continued both superiorly and inferiorly in the medial direction to the opposite side. There was no evidence of surrounding tissue infiltration. The internal jugular vein and common carotid artery were identified on the right side. The external carotid artery was traced and the feeding vessels ligated. The tumor was removed completely which weighed $1.7 \mathrm{~kg}$. The defect was closed primarily. The postoperative course was uneventful. The histopathology report grossly stated that the mass had a lobulated irregular outer surface, and was covered by skin flap measuring approximately $15 \mathrm{~cm} \times 13 \mathrm{~cm}$. Cut section of the mass showed solid, gray-white, mucinous, and myxoid areas with necrosis. Microscopic examination revealed a loss of normal architecture of the salivary gland with chondromyxoid stroma and epithelial cells in sheets and forming glands suggestive of pleomorphic adenoma. There was no detected atypia or malignancy in any dissected area with no evident mitotic figures nor metaplastic elements.

The patient presented good aesthetic and functional results with no clinical and radiographic evidence of recurrence (Figs 4 and 5).

\section{Discussion}

Salivary gland tumors constitute $3-4 \%$ of the head and neck cancers, out of which $8-22 \%$ are seen in the submandibular salivary gland. ${ }^{6}$ Most common neoplasm of the submandibular gland is pleomorphic adenoma which is a benign mixed tumor. ${ }^{7}$ These are also the most common benign salivary gland tumors and classified as mixed due to the epithelial and mesenchymal components. $^{4}$

In a study of 25 submandibular neoplasms done by Ethunandan et al., FNAC accurately identified $78 \%$ of benign tumors but no malignant tumors. ${ }^{8}$ Hence FNAC before the surgery

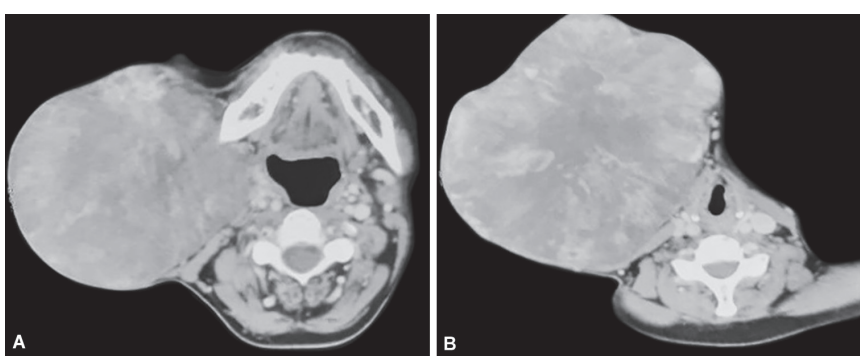

Fig. 2: Computed tomography scan neck axial view showing a lobulated large heterogeneously enhancing mass in the right submandibular salivary gland

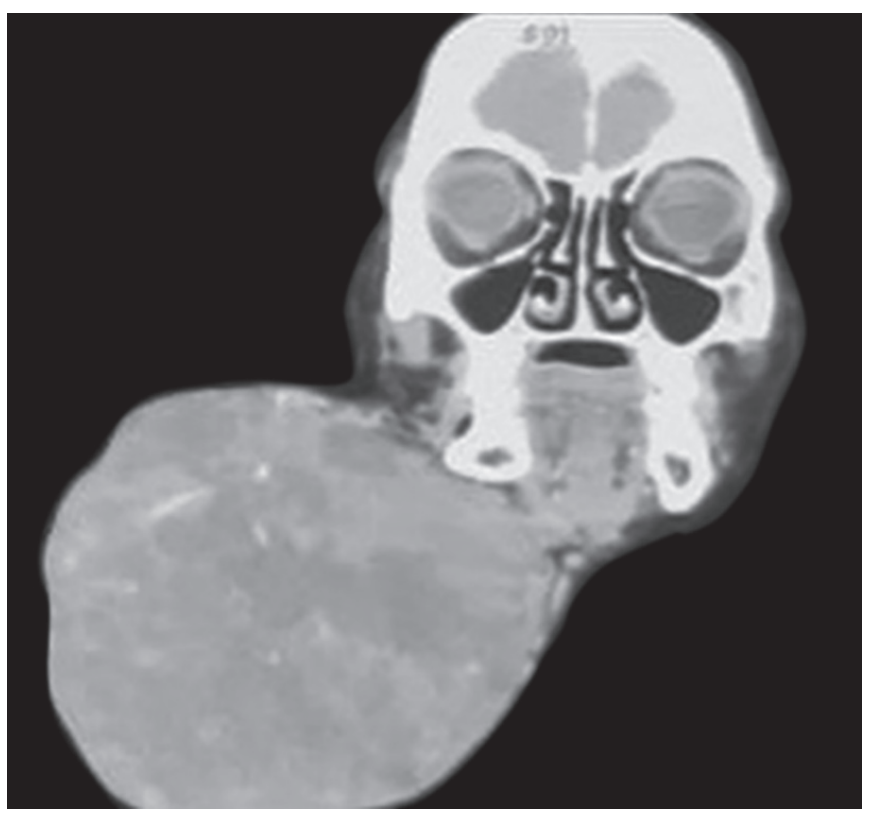

Fig. 3: Computed tomography scan neck coronal view showing a large lobulated heterogeneously enhancing mass in the right submandibular salivary gland

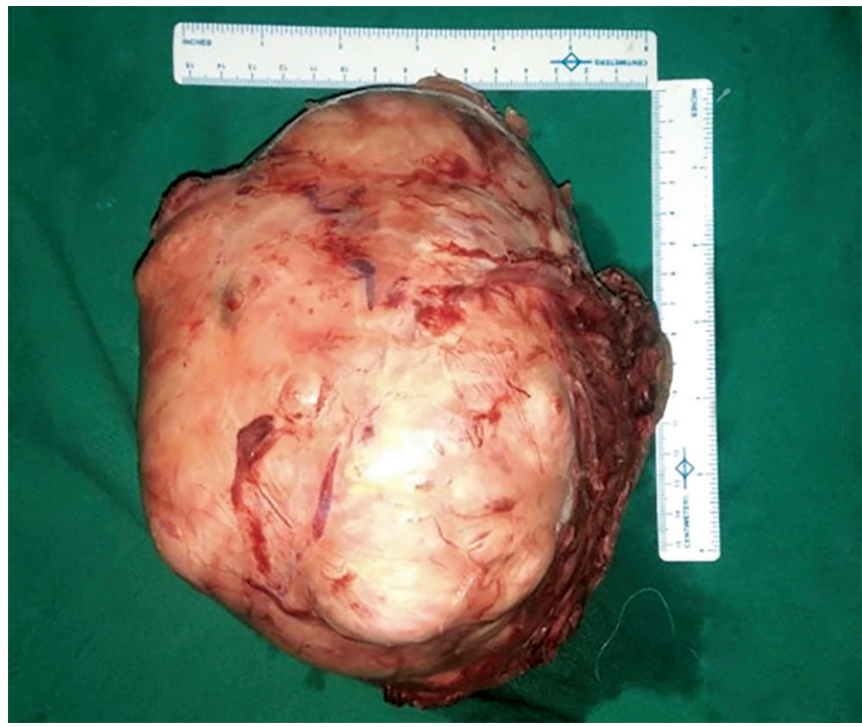

Fig. 4: Gross specimen of tumor 


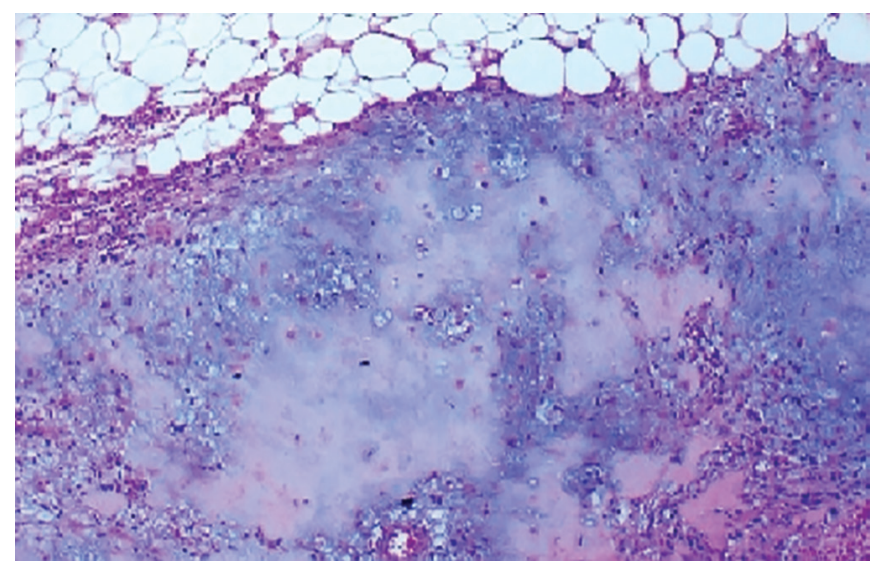

Fig. 5: Histopathological picture of the tumor with chondromyxoid stroma and myoepithelial cellular areas

can be useful from a medicolegal perspective. These tumors are usually painless, smooth, firm, and asymptomatic until they attain major sizes. Buenting et al., in a study of 10 largest pleomorphic adenomas, found a mean tumor weight of $7.8 \mathrm{~kg}$, nine of 10 occurring in females, with a mean age of 56 years. ${ }^{9}$ In our case, the patient was a female with an age of 52 years and a tumor weight of $1.7 \mathrm{~kg}$.

Being painless and slowly growing, some patients neglect it to such large sizes especially if surgery was a psychological setback for them which can then lead to facial disfigurement and severe pressure symptoms which may be fatal. Gupta et al. reported weights of pleomorphic adenomas ranging from 1 to $27 \mathrm{~kg} .{ }^{10}$ Imaging studies such as CT and/or MRI can give a probable diagnosis. Pleomorphic adenomas are well demarcated from the surrounding tissue by a pseudocapsule due to compression of the surrounding parenchyma and fibrosis. ${ }^{11}$ This fibrous capsule has to be completely excised to prevent recurrence. ${ }^{11}$ Giant tumors have a lobulated appearance, which supports the diagnosis.

The incidence of malignant transformation in adenomas ranges from 1.9 to $23.3 \% .^{12}$ The risk increases with a long history of appearance, recurrence, the advanced age of the patient, and location in the major salivary gland. ${ }^{13}$

\section{Conclusion}

Giant pleomorphic adenoma of the submandibular gland is a rare finding and should be diagnosed cautiously. Proper treatment is complete surgical excision with removal of the fibrous capsule so as to prevent recurrence. Presenting such cases highlights the problem of many patients especially in the developing countries who neglect such conditions.

\section{Clinical Significance}

Being benign, if properly diagnosed on time and managed well surgically, it gives tremendously good results regarding cosmetics and recurrence of the disease. But due to its painless and slowly growing character, some patients neglect it to such large sizes, especially if surgery is a psychological setback for them which can then lead to facial disfigurement and severe pressure symptoms which may be fatal.

\section{Conflict of Interests}

The authors declare that they have no known competing financial interests or personal relationships that could have appeared to influence the work reported in this paper.

\section{References}

1. Mendenhall WM, Mendenhall CM, Werning JW, et al. Salivary gland pleomorphic adenoma. Am J Clin Oncol 2008;31(1):95-99. DOI: 10.1097/COC.0b013e3181595ae0.

2. Pinkston JA, Cole P. Incidence rates of salivary gland tumors: results from a population-based study. Otolaryngol Head Neck Surg 1999;120(6):834-840. DOI: 10.1016/S0194-5998(99)70323-2.

3. Molina EJ, Mayer K, Khurana J, et al. Pleomorphic adenoma of the submandibular gland. J Pediatr Surg2008;43(6):1224-1226. DOI: 10.1016/j.jpedsurg.2008.01.056.

4. Spiro RH. Salivary neoplasms: overview of a 35-year experience with 2,807 patients. Head Neck Surg 1986;8(3):177-184. DOI: 10.1002/ hed.2890080309.

5. Seifert G, Miehlke A, Haubrich J, et al. Diseases of the salivary glands. New York: Thieme; 1986. p. 408.

6. Al-Khateeb TH, Ababneh KT. Salivary tumors in north Jordanians: a descriptive study. Oral Surg Oral Med Oral Pathol Oral Radiol Endod 2007 May 1;103(5):e53-59. DOI: 10.1016/j.tripleo.2006.11.017.

7. Tortoledo ME, Luna MA, Batsakis JG. Carcinomas ex pleomorphic adenoma and malignant mixed tumors: histomorphologic indexes. Arch Otolaryngol 1984 Mar 1;110(3):172-176. DOI: 10.1001/ archotol.1984.00800290036008.

8. Ethunandan M, Davies B, Pratt CA, et al. Primary epithelial submandibular salivary gland tumours-review of management in a district general hospital setting. Oral Oncol 2009;45(2):173-176. DOI: 10.1016/j.oraloncology.2008.04.011.

9. Buenting JE, Smith TL, Holmes DK. Giant pleomorphic adenoma of the parotid gland:case report and review of the literature. Ear Nose Throat J 1998 Aug;77(8):634, 637-638, 640. DOI: 10.1177/014556139807700812.

10. Gupta M, Chaudhary N, Gupta M. Giant presentation of pleomorphic adenoma in major salivary gland. BMJ Case Rep $2011 \mathrm{Jul}$ 4;2011:bcr0420114098. DOI: 10.1136/bcr.04.2011.4098.

11. Abdelkhalek M, Elmetwally M, Mazy A, et al. Gigantic submandibular pleomorphic adenoma: a rare case report. Int J Surg Case Rep 2019 Oct 24;65:91-96. DOI: 10.1016/j.ijscr.2019.10.033.

12. Perumal CJ, Meyer M, Mohamed A. A giant pleomorphic adenoma of the submandibular salivary gland: a case report Craniomaxillofac Trauma Reconstr 2012;5(3):185-188. DOI: 10.1055/s-0032-1322530.

13. Yamamoto Y. Clinical signs and histology of carcinoma in pleomorphic adenoma. Otologia 1994;87:1320-1324. 